\title{
Compositional Analysis, Antioxidant Assesment, and Antimicrobial Activity of Extracted Essenstial Oil from Vitex Trifolia
}

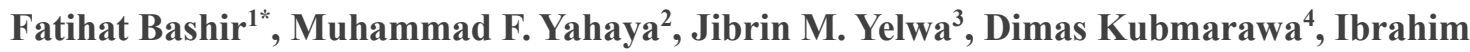 \\ Gidado $^{5}$ \\ ${ }^{I}$ General Murtala Ramat Muhammad Secondary School, Yola, Adamawa State, Nigeria. \\ ${ }^{2}$ Department of Petroleum Chemistry and Engineering, American University of Nigeria, Yola, Adamawa State, \\ Nigeria. \\ ${ }^{3}$ Department of Scientific and Industrial Research, National Research Institute for Chemical Technology, \\ Zaria, Kaduna State, Nigeria. \\ ${ }^{4}$ Department of Chemistry, Modibbo Adama University Yola, Adamawa State, Nigeria. \\ ${ }^{5}$ Adamawa State University, Mubi, Adamawa State, Nigeria.
}

*Corresponding Author: Fatihat Bashir, General Murtala Ramat Muhammad Secondary School, Yola, Adamawa State, Nigeria.

\begin{abstract}
The chemical composition, antioxidant profile and antimicrobial activities of extracted essential oil Vitex trifolia were investigated. Phytochemical screening was conducted using standard qualitative techniques, while the essential oil was extracted from the Vitex trifolia by modified steam distillation apparatus. The plant extract was tested to investigate its chemical composition, antioxidant, and antimicrobial profiles. Phytochemical analysis of the extract showed presence of major classes of phytochemicals. Gas chromatography-mass spectrometry results revealed presence of 15 phytoconstituents in the essential oil. In vitro antioxidant activities of Vitex trifolia essential oil exhibited a very strong free radical scavenging activity, $50 \mu \mathrm{L} / \mathrm{ml}(79.21 \%)$ which indicates, Vitex trifolia is less effective antioxidant compared to the standard (Ascorbic acid) having scavenging activity of $98.74 \%$. The result of the antimicrobial test shows the inhibitory effect of the essential oil of Vitex trafolia is seen only in Salmonella aureus. Results of this study show that Vitex trifolia is a rich source of phenolic compounds that can play an important role in preventing the progression of many diseases.
\end{abstract}

Keywords: Vitex trafolia, antioxidant, antimicrobial, larvicidal, chemical composition.

\section{INTRODUCTION}

Medicinal plant is defined as any plant which in one or more of its organ contain substances that can be used for therapeutic purposes or which are precursors for the synthesis of useful drugs(Sofowora,1982). This definition has set a difference between medicinal plants whose medicinal value have been tested and their medicinal constituents have been studied and plants that are regarded as medicinal but have not been studied scientifically. However, through trial and error, humans have learned that under certain condition, physiological effects of some secondary metabolites can have curative benefits or narcotic effects (Wink, 1999).

Vitex trifolia is a shrub or shrubby tree that may grow up to 6 meters in height. Its origin is unknown and several varieties have been described in countries as are apart as India and Mexico. Vitex are reported to possess antidysentery, analgesic, anti-inflammatory and anti-tumor activities and they are used in folk medicine for the treatment of scorpion stings and gastrointestinal disorders. In the Ayurveda and Unani systems of medicine, the leaves and seeds are widely used for the treatment of rheumatism and inflammatory joint conditions (Argueta et al., 1994). The anti-inflammatory potential of an aqueous extract of Vitex trifolia leaves was evaluated by monitoring its effects on the modulation of cytokines, mediators of inflammation, as well as on the expression profiles of inducible nitric oxide synthase, 
which produces the free radical nitric oxide. The leaves are used internally or externally in baths to cure Ciguatera fish poisoning-related pruritus. It is used as an anti-pyretic, anti-inflammatory, and nematicidal agent and to increase body weight and it has also been reported to have anti-tumor activity (Aranda et al., 1999).

Essential oils are defined by ISO as the products obtained from different parts of plants through distillation by steam distillation, hydro distillation and pressing the citrus fruit pericarp techniques. They are complex mixtures of volatile and lipophilic substances, formed by the secondary metabolism of plants characterized by a pleasant odor most of them presented (Simeos et al., 2007). Essential oils are marketed by various companies as raw material for various products with applications in perfumery, cosmetics, foods, and as adjuncts in medicines, among others. (Simeos et al., 2007).

Anti-oxidants are molecules capable of inhibiting the oxidation of other molecules. Oxidation a chemical reaction that transfer electrons from a substance to an oxidizing agent (Fukumota and Mazza. 2000) produces free radicals which in turn start chain reaction that damages cell. This oxidation basically, has been implicated as one of the mechanism of action of diabetes disease (Maestri et al., 2006).

Antioxidant on the other hand interfere with the chain reaction by removing free radicals intermediate and inhibit other oxidation reaction: Generally, the relative interaction between the different antioxidant is a complex one with the various metabolites and enzymes having synergistic and inter dependent effects on one another. Therefore, the action of one antioxidant may depend on the proper functioning of other members of the antioxidant system (Sie, 1997).

In the recent decades, antimicrobial plant products have gained a special attention because of increase resistance to antibiotics acquired of some microorganisms (Hussain et al., 2008). With the growing interest in the use of essential oils in both the food and the pharmaceutical industries, a systematic examination of plant extracts for these properties has become increasingly important. The use of natural antimicrobial compounds is important not only in the preservation of food but also in the control of human and plant diseases of microbial origin (Baratta et al., 1998).

\section{Materials AND EQUiPMENTS}

Fresh leaves of Vitex trifolia, GC-MS Machine, Steam distillation apparatus, Heat source, Laboratory glass wares, and reagents of analytical grade.

\subsection{Materials}

\subsubsection{Sample collection, Authentication and Preparation}

Fresh fruit of Vitex trifolia were collected from Moddibo Adama University of Technology, Yola, located in the North-Eastern part of Nigeria. The leaves were air dried

\subsubsection{Microorganisms}

E. coli, S. aureus, P.aeruginosa, K. pneumonia and S.typhi

\subsection{Methods}

\subsubsection{Extraction of Essential Oils}

$500 \mathrm{~g}$ of the pulverized form of the fresh samples was subjected to steam distillation in a modified steam distiller (as modified by Runde et al., 2015) according to the British Pharmacopoeia (BP) method. The time taken for the isolation of the oil was 4 hours (Yahaya, et al., 2018).

\subsection{Characterization}

\subsubsection{Phytochemical Screening of the Extract}

The extract was analysed for the presence of Phenol, Resins, Terpenoids, Glycosides, Essential oil, Alkaloid, Flavonoid, Tannins and Saponnins using standard qualitative method as described by various authors and adopted by (Kubmarawa et al., 2007).

\subsubsection{Gas chromatographic mass spectrometry (GC/MS)}

GC-MS analysis was performed as adopted by Runde et al. (2015) on a J and W Scientific gas chromatography directly couple to the mass spectrometer system (model GC Agilent S/N 20102969, polarise Q S/N 210729) HP 5ms 5\% pheny! Methyl] silox: 469.56. Capillary Colum (30M x 250m) was used under the following condition: ovum temperature $500 \mathrm{C}$ for $1 \mathrm{~min}$, then 10 and $20 \mathrm{~min}$ to $3000 \mathrm{C}$ for $2 \mathrm{~min}$ and the descriptions is as follows. 
Injector temperature $2300 \mathrm{C}$ carrier gas $\mathrm{He}$, flow rate $1 \mathrm{~m} / \mathrm{min}$; the volume of the injected sample was $0.2 \mathrm{~L}$ of diluted oil in hexane. Split less injection techniques, ionization energy $70 \mathrm{ev}$. In the electron ionization (EI) mode, ion source temperature $2300 \mathrm{C}$ scan mass range of M/Z 60-335; the constituents of the essential oils were identified base on comparison of the retention indices and mass spectra of most of the compound with data generated under identical experimental conditions by applying a twodimensional search algorithm considering the retention index as well as mass spectra similar with those of authentic compounds available in NBS75K Library.

The retention indices (RI) are in relation to a homologues series of n-alkanes on the GC column under the same chromatographic condition components relative concentration will be obtained by peak area normalization (Ramzi et al., 2013).

\subsubsection{Determination of Antimicrobial Activity}

The antimicrobial activity of the extract was determined using Disc Diffusion Method (Ravi et al., 2010., Baur et al., 1966: Wilkins et al., 1972., Mitscher et al., 1972). Petri plates containing 10ml of Mueller Hinton agar medium was seeded with 24 hours old culture of a selected bacteria strain. Sterile filter paper disc (9mm in diameter) containing 1000-5000 ppm of a plant essential oil dissolved in Dimethyl sulphur oxide (DMSO) will be placed on the medium. DMSO and water alone served as negative controls. A standard disc containing chloramphenicol antibiotic drug $(30 \mu \mathrm{g} / \mathrm{disc})$ was used as a positive control. Incubation was done for 14 hours at $37^{\circ} \mathrm{C}$. The assessment of antimicrobial activity based on the measurement of diameter of incubation zone formed around the disc (diameter of inhibition zone minus diameter of the disc). An average zone of inhibition was calculated for three replicates. An inhibition zone of $8 \mathrm{~mm}$ or greater was considered as a good antimicrobial activity (Ali et al., 2001). According to Ogunwande, 2001 a cleared zone $>10 \mathrm{~mm}$ will be interpreted as sensitive while $<9 \mathrm{~mm}$ will be interpreted as resistance. Essential oils that showed positive activity in the preliminary screening was serially diluted (two-fold) and loaded on the filter paper disc. These serially diluted concentrations of the extracts will be assayed in triplicate as described above to determine the Minimum Inhibitory Concentration (MIC) which is the minimum concentration per disc to inhibit growth of the test microorganism (Habsah et al., 2000).

\subsubsection{DPPH free radical scavenging assay of Essential oil}

The 2, 2-diphenyl-1-picrylhydrazyl (DPPH) free radical scavenging assay was carried out for the evaluation of the antioxidant activity of the various essential oils. The purple color, typical for free DPPH radical fades, and the change in absorbency at $\lambda=517 \mathrm{~nm}$ is measured spectrophotometrically.

The method was carried out as described previously by Kubmarawa et al. (2013) and adopted by Runde et al. (2015). The essential oil was dissolved in methanol, and various concentrations $(2,6,12,24$, and $50 \mu \mathrm{L} / \mathrm{mL}$ ) was used. The assay mixture contained in a total volume of $1 \mathrm{~mL}, 500 \mu \mathrm{L}$ of the oil, $125 \mu \mathrm{L}$ prepared DPPH ( $1 \mathrm{mM}$ in methanol), and $375 \mu \mathrm{L}$ solvent (methanol). After $30 \mathrm{~min}$ incubation at $25^{\circ} \mathrm{C}$, the decrease in absorbance was measured at $\lambda=517 \mathrm{~nm}$. The radical scavenging activity was calculated from the equation below: $\%$ or radical scavenging $=[($ Abs control - Abs Sample $) \div$ Abscontrol $] \times 100$ (Runde et al., 2015).

\section{RESULTS AND DISCUSSION}

Table1. Phytochemical screening of Vitex trifolia

\begin{tabular}{lllllllll} 
Alkaloids Essential oil Flavonoids & Glycoside Phenols Saponnins Tannins Terpenoids \\
\hline+ & + & + & + & + & - & + & + \\
\hline
\end{tabular}

Key $+=$ Present, $-=$ Absent

\subsection{Chemical Composition of Essential oil of Vitex trifolia}

The GC-MS analysis of the essential oil obtained from the leaves of Vitex trafolia shows the presence of the following compounds in table 2 below. The major constituents are Caryophyllene (22.78\%), 
Bicyclo[3.1.0],4-methylene-1-(1-methylethyl)hexane(27.38\%),Bicyclo[3.1.1]3,6,6-trimethylhept-2ene(7.67\%),1,2,3,4,4a,5,6,8a-octahydro-7-methyl-4-methylene-1-(1-methylethyl)

Naphthalene(5.23\%), alpha.-Caryophyllene(4.90\%), 1,2,3,5,6,8a-hexahydro-4,7dimethyl-1-(1methylethyl)-Naphthalene(3.52\%), decahydro-4a-methyl-1-methylene-7-(1-methylethyl)-

Naphthalene(4.14\%), beta-pinene(3.52\%), beta.-Phellandrene(3.52\%). Bicyclo[3.1.0],2-methyl-5-(1methylethyl)- hex-2-ol (1.03\%). Similarly, work by another researcher shows 1,8-Cineol (17.16\%), Caryophyllene (8.60\%) and Terpinen-4-ol (10.22\%) as the major components of essential oils obtained from the flower of vitex agnus castus (Abdullahi et al.,2016). Another researcher also revealed that the major components of vitex agnus castus leaves essential oils 1,8 Cineol(17.38\%),Sabinene (15.38\%) and Caryophyllene (18.76\%). The difference in chemical composition reported by the two authors is a clear effect of environmental influence on chemical constituents of essential oil.

Table2. GC-MS analysis of the essential oil from Vitex trifolia.

\begin{tabular}{|l|l|l|l|}
\hline Constituent & RT & Area\% & MW \\
\hline Bicyclo[3.1.1]3,6,6-trimethy hept-2-ene 1-(+) & 2.299 & $7.67 \%$ & 136 \\
\hline $\begin{array}{l}\text { Bicyclo[3.1.0]4-methylene-1-(1- } \\
\text { methylethyl)- hexane(sabinene) }\end{array}$ & 3.010 & $1.03 \%$ & 136 \\
\hline $\begin{array}{l}\text { Bicyclo[3.1.0]2-methyl-5-(1-methylethyl)- } \\
\text { hex-2-ol }\end{array}$ & 2.691 & $27.58 \%$ & 136 \\
\hline 1,4-cyclohexadiene & 3.410 & $1.13 \%$ & 136 \\
\hline 3-cyclohexan-1-ol,4-methyl-1-(1-methylethyl) & 4.688 & $0.35 \%$ & 154 \\
\hline $\begin{array}{l}\text { 3-cyclohexene-1-methanol,a,a,4- } \\
\text { methylacetate }\end{array}$ & 9.475 & $0.37 \%$ & 140 \\
\hline $\begin{array}{l}\text { Napthalene,1,2,4a,5,6,8a-hexahydro-4- } \\
\text { dimethyl-1-(1-methylether) }\end{array}$ & 7.797 & $2.39 \%$ & 204 \\
\hline Caryophylene & 6.938 & $22.78 \%$ & 204 \\
\hline Alpha caryophylene & 7.134 & $4.90 \%$ & 204 \\
\hline $\begin{array}{l}\text { 1,2,3,4,4a,5,6,8a-octahydro-7-methyl-4- } \\
\text { methylene-1- Napthalene }\end{array}$ & 7.357 & $5.23 \%$ & 204 \\
\hline $\begin{array}{l}\text { 1,2,3,5,6,8a,hexahydro-4,7-dimethyl-1-(1- } \\
\text { methylethyl) Napthalene }\end{array}$ & 7.641 & $3.52 \%$ & 204 \\
\hline Globulol & & & 222 \\
\hline Benzylbenzoate & 9.998 & $0.53 \%$ & 212 \\
\hline Beta pinene & 3.142 & $3,52 \%$ & 136 \\
\hline Camphene & 6.171 & $0.82 \%$ & $0.17 \%$ \\
\hline Isocaryophylene & 10.873 & & \\
\hline
\end{tabular}

\subsection{Antioxidant (DPPH Radical Scavenging) Activity}

From the result, the scavenging ability of the essential oils showed a concentration-dependent activity profile (Table 3). The Vitex trifolia essential oil exhibited a very strong free radical scavenging activity, $50 \mu \mathrm{L} / \mathrm{ml}(79.21 \%)$ which indicates, Vitex trifolia is less effective antioxidant compared to the standard (Ascorbic acid) having scavenging activity of $98.74 \%$. Similar work shows that the antioxidant activities of the essential oils of cympobogon citratus examined using DPPH scavenging test and the highest inhibition was obtained from the essential oil extracted from the stalk (89.5\%)and the major components are geranial $(32.10 \%$ and $29.64 \%)$, neral $(22.36 \%$ and $21.73 \%)$, geraniol $(5.40 \%$ and $7.75 \%$ ), limonene (5.71\% and 5.92\%) and $\beta$-myrcene (2.20\% and $2.28 \%$ ), were the major constituents of the stalks and leaves' lemongrass essential oil respectively, (Mirghani et al,. 2012). A plot of $\%$ inhibition against concentration $(\mu \mathrm{L} / \mathrm{ml})$ is shown in the figure below.

Table3. DPPH Radical scavenging activity

$\%$ scavenging property/ $\mu \mathrm{L}$

\begin{tabular}{lccccc}
\hline & 2 & 6 & 12 & 24 & 50 \\
\hline Vitex trifolia & 76.13 & 76.70 & 76.76 & 77.95 & 79.21 \\
Ascorbic acid & 80.22 & 83.06 & 85.01 & 92.44 & 98.74 \\
\hline
\end{tabular}




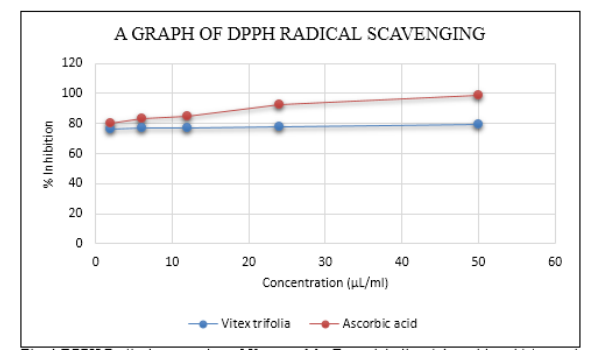

Fig1. DPPH Radical scavenging of Vitex trafolia Essential oil and Ascorbic acid (control

\subsection{Antimicrobial Activity of Vitex trifolia Essential oil}

The antimicrobial screening of Vitex trifolia essential oil was carried out using disc diffusion methods. The result in Table 4 shows the inhibitory effect of the essential oil of Vitex trafolia is seen only in Salmonella aureus. The results of this work can be related to the antibacterial activity of the essential oils of commonly consumed medicinal herbs using an invitro model presented that all the oils tested in the disc-diffusion method showed bacteriostatic activity in the essential oils of Lemon oil 9.0-19.0 mm and orange oil has inhibition zone within the range of $8.0-19.0 \mathrm{~mm}$ and did not show inhibition against $P$. aeruginosa and $P$. mirabilis. (Marina et al., 2010).

Table4. Result of Antimicrobial Activity of Vitex trifolia Essential oil

\begin{tabular}{|l|c|}
\hline Micro organisms & Vitex trifolia Extract \\
\hline E. coli & - \\
\hline S. aureus & + \\
\hline P.aeruginosa & - \\
\hline K. pneumoniae & - \\
\hline S.typhi & - \\
\hline
\end{tabular}

Key- $+=$ Resistance, ++ and $+++=$ Sensitive, $-=$ No inhibition .

\section{CONCLUSION}

In the present study, 15 compounds were identified from the Vitex trifolia essential oil by using GCMS analysis. Presence of various bioactive compounds in the extracts justifies the use of this plant for various ailments by traditional medicinal practioners. Further investigation into isolation of pure compounds and pharmacological studies were needed to give fruitful results. From the above results, it could be recommended as a plant of phytopharmaceutical importance.

\section{REFERENCES}

[1] Abdullahi H., Khaled S.,Naseer B.,Abdulkarim C.and Hassan Y.A.(2016). Essential oils and chemical composition of Vitex agnus castus .l.from southern-wesy Algeria and its antimicrobial activity.Benthan science publishers,4837-4879.

[2] Aranda, E., Hernandez, M.M., Heraso C., Villarreal, M.L. and Arispuro, I.V. (1999). Biological activities of crude plant extracts from Vitex trifolia L. Journal of Ethnopharmacology, 67(1): 37-44.

[3] Argueta, A., Cano, L.M. and Rodarte, M.E. (1994). Atlas de las Plantas de la Medicina Traditional I y III. Instituto Nacional Indigenista, 537-538.

[4] Baratta, M.T., Dorman, H.J.D., Deans, S.G., Figueiredo, A.C., Barroso, J.G. and Ruberto, G. (1998). Antimicrobial and antioxidant properties of some commercial essential oils. Flavour and Fragrance Journal 13: $235-244$.

[5] Hussain, A.I., Anwar, F., Sherazi, S.T.H., Przybylski, R. (2008). Chemical composition, antioxidant and antimicrobial activities of basil (Ocimum basilicum) essential oils depends on seasonal variations.

[6] Kubmarawa, D., Ajoku, G.A., Enwerem, N.M. and Okorie, D.A. (2007); Preliminary Phytochemical and Antimicrobial screening of 50 Medicinal plants from Nigeria. African Journal of Biotechnology. 6(14), 1690-1696

[7] Kubmarawa, D., Akiniyi, J.A. and Okorie, D.A. (2013). Ethnomedicinal survey of traditional medicine of Lala people of Nigeria. International Journal of Medicinal plant and Alternative Medicine, 1(3), 39-57.

[8] Maestri, D.M., Nepotei, V., Lamarque, A.L. and Zygadlo, J.A. (2006). Natural products as antioxidants. Phytochemistry: Advances in Research, Ed: Filippo Impirato. Research Signpost. India pp.105-135. 
[9] Marina Soković, Jasmina Glamočlija, Petar D. Marin, Dejan Brkić and Leo J. L. D. van Griensven (2010). Antibacterial Effects of the Essential Oils of Commonly Consumed Medicinal Herbs Using an In Vitro Model. J.Ess.Oil.Res.15, 7532-7546.

[10] Mirghani, M. E. S., Liyana, Y. and Parveen, J.(2012).Bioactivity analysis of lemongrass (Cymbopogan citratus) essential oil. International Food Research Journal 19(2): 569-575.

[11] Muhammad F. Yahaya, Dimas Kubmarawa, Jibrin M. Yelwa and Musa Runde (2018): Antioxidant and antimicrobial activity of essential oils extracted from aromatic plants. World Scientific News. An International Scientific Journal. Pp 14-22.

[12] Ogunwande, I.A., Guido, F., Olubusayo, O., Alese, P.L., Akintayo, L.O. and Williams, N.S. (2011); A new chemical form of essential oil of hyssopus officinalis (Lamiceal); Int. J. Biol chem Sci 5(1) 46-55.

[13] Ramzi, A. M., Mansour, S. A., Mohammed, A. A., Adnan, J. A. and Jamal, M. K. (2013). GC and GC/MS Analysis of Essential Oil Composition of the Endemic Soqotraen Leucasvirgata. and Its Antimicrobial and Antioxidant Activities. Int. J. Mol. Sci. 14(11), 23129-23139

[14] Ravi, K.U., Pratibha, D. and Shoeb, A. (2010); Screening of Antibacterial Activity of six Plant Essential Oils against Pathogenic Bacterial Strains. Asian Journal of Medicinal Science. 2(3), 152-158

[15] Runde, M., Kubmarawa, D. and Maina, H. (2015) Compositional analysis and Antimycobaterium Tuberculosis Activity of Essential oil of Hyptis Suaveolens LAMICEAE. Res. J. of Chem. Sci. 5(7), 1- 4

[16] Sie, H. (1997). Oxidative Stress: Oxidants and Antioxidant, Exp.Physiol; 82(82), 291-295.

[17] Sofowora, A. (1982) Medicinal Plants and Traditional Medicine in Africa. Wiley, New-York. 10-13.

[18] Wink, M. (1999) Function of secondary metabolites, in function of plant secondary metabolites and their exploitation in Biotechnology, annual plant reviews, Sheffield Academic Press, Sheffield U.K; (3), 1-16.

Citation: Fatihat Bashir, et.al., (2019). Compositional Analysis, Antioxidant Assesment, and Antimicrobial Activity of Extracted Essenstial Oil from Vitex Trifolia. International Journal of Medicinal Plants and Natural Products (IJMPNP), 5(3), pp.29-34. http://dx.doi.org/10.20431 /2454-7999.0503005

Copyright: () 2019Authors, this is an open-access article distributed under the terms of the Creative Commons Attribution License, which permits unrestricted use, distribution, and reproduction in any medium, provided the original author and source are credited. 